\title{
Low Fertility and Contraceptive Sterilization: The Canadian Case
}

\author{
Laurence Charton \\ Université de Strasbourg, France \\ Evelyne Lapierre-Adamcyk \\ Université de Montréal \\ Montréal, Québec, Canada \\ E-mail: evelyne.lapierre-adamcyk@umontreal.ca
}

\begin{abstract}
This article presents fertility variations among the Canadian regions and analyses the paths leading to the choice of contraceptive sterilization. Based on data from the 2001 General Social Survey, the research shows that while every region has adopted a low fertility regime, substantial differences are observed among women aged 40-49 in 2001: Quebec couples had fewer children; among those in stable unions, Quebec couples were also more likely to choose contraceptive sterilization, while this was not the case among those couples where at least one of the spouses was in a second union; moreover, couples in such unions were less likely to have a common child in Québec than in other regions. In the end, if regional differences in the choice of sterilization persist, they are not large, and this choice is driven by fertility decisions everywhere.
\end{abstract}

Key Words: Below replacement fertility, contraceptive sterilization, Canada 


\section{Résumé}

Cet article présente les variations de la fécondité observées dans les régions canadiennes et analyse les étapes qui conduisent au choix de la stérilisation contraceptive. Fondée sur les données de l'Enquête sociale générale de 2001, cette recherche démontre que, en dépit du fait que toutes les régions aient adopté un régime de faible fécondité, des différences substantielles subsistent chez les femmes de 40-49 ans en 2001: les couples québécois ont moins d'enfants que dans les autres régions; dans les unions stables, les Québécois sont plus susceptibles de choisir la stérilisation contraceptive, ce qui n'est pas le cas des couples où l'un des conjoints est dans une seconde union; de plus chez ces derniers, la probabilité d'avoir un enfant commun est plus faible au Québec que dans les autres régions. Enfin, si les différences régionales persistent quant au choix de la stérilisation, elles ne sont pas très grandes, et ce choix est partout dicté par les décisions en matière de fécondité.

Mots-clés: Taux de fécondité à la baisse, stérilisation contraceptive, Canada

\section{Introduction}

Since the 1990's, low fertility has become a persistent phenomenon in most developed societies (Ram 2007). In Canada in particular, over 60 years, fertility has declined rapidly. In little more than 10 years, the total fertility rate went from a peak close to 4 children per woman in 1959 to about 2 children per woman in 1972. For the last two decades, the TFR remained below replacement level. Canada is a vast and complex country, and long standing fertility differentials have been observed by regions throughout the last century. Historical analysis drawn from census data on the number of children born to women has shown that province or regional differences were associated with many socioeconomic and cultural features, such as rural-urban divide, education, income, but mostly religion and language (Charles 1948; Henripin 1968). Despite the persistence of social and cultural features among regions, all have adopted a low fertility regime; even in such circumstances, as we will see, variations are still present, but some well known traditional features have been reversed, for example the higher fertility of Québec, mostly French-speaking Catholics, compared to other Canadians, has now become one of the lowest among Canadian regions. 
Low fertility in Western societies has frequently been studied, both its quantum and tempo, especially in terms of period measures, and various theoretical frameworks have been proposed to enlighten our understanding of its causes. Some of these theoretical developments came from the necessity to understand the transition between high and low fertility levels. Others were geared to establish the conditions allowing societies to maintain low fertility aspirations and behaviour among men and women. Morgan and Taylor (2004) proposed to regroup relevant theoretical frameworks in 6 types. These are contributions stressing: a) economic change; b) the import of ideological change; c) institutional change and differences; d) technological change; e) multiple domains and/or their interactions; f) path dependence and idiosyncratic explanations. Testing these various theories has produced a large body of knowledge, and Morgan and Taylor are right in saying that we do know a lot about low fertility, in particular if one takes also in consideration the more descriptive work based on total fertility decomposition, using the proximate determinants approach. Nonetheless, these authors think that more can be documented and discovered by the analysis of specific questions based on individual societies.

In particular, approaching fertility through the significance that a child has in the life of a couple - the child's place among other expectations - might provide new insights in understanding low fertility. The traditional family needed children, and generally many children, to ensure its survival and reproduction. The present-day family needs fewer children to realize parents' projects and self-fulfilment. Moreover, many of the family expectations seem incompatible in the contemporary circumstances with the presence of more than two children. Hence, one should not try to explain fertility only in terms of external factors to the family; one should rather try to understand it as the optimum strategy by which the couples may best achieve all their plans.

In demographic terms, there may be different strategies to accomplish these projects. One of them may be, for couples, to voluntarily put an end to their reproductive capacity when they do not want more children, either because they consider having reached the desired family size or because they give priority to other projects that do not allow the arrival of another child.

In this paper, the underlying hypothesis is that the use of contraceptive sterilization may become a strategy for achieving those plans. Its theoretical justification lies with the idea that technological change has been an important element in the adoption of low fertility regime (Potts 1997). Indeed, among technological change, the development of effective contraceptive methods, the availability of microsurgery allowing contraceptive sterilization for both men and 
women and of modern techniques of abortion have played a key role in the persistence of sub-replacement fertility. The specific goal of this article is to look at the relationship between low fertility and contraceptive sterilization, a quasi non-reversible contraceptive mean, which couples undergo when they feel they have achieve their fertility aspirations (Marcil-Gratton 2000; Charton and Lapierre-Adamcyk 2007, 2008b). Under this assumption, it may be interesting to see if using this method can have an impact on the final level of general fertility in a society.

Contraceptive sterilization is a highly effective method to avoid unintended pregnancies and eventually undesired births for those who do not want to have an abortion. Its use has become widespread in many areas, both in developed and developing countries, and it has been especially popular in North America (Bumpass et al. 2000; MarcilGratton 2000; Godecker et al. 2001, Krishnan 2004). Most of people reporting choosing sterilization over a reversible method generally explain it because it is most secure to prevent a pregnancy (Brown and Eisenberg 1995). Couples often choose vasectomy over tubal ligation because the procedure seams simpler and safer (Magnani 1999). Barone et al. (2000) observe also that men choose vasectomy in the same proportion, whatever their socio-economic and cultural characteristics are. Moreover, Godecker et al. (2001) show that tubal ligation increased in past decades, because women recently spent greater proportions of their lives outside of marriage or in less-stable cohabiting partnerships than they did in the past. Furthermore, according to Bumpass et al. (2000), the parity at the time of the last wanted birth is a major factor influencing sterilization, while Kaufman (1998) shows that the number of children has a curvilinear effect on sterilization, increasing up to four children then decreasing from the fourth children and above.

The approach retained in this article aims at shedding light on the relationship between paths leading to low fertility, including contraceptive sterilization, using data on five regions in Canada: Atlantic, Québec, Ontario, Prairies and British Columbia.

The article starts with a descriptive presentation of the fertility quantum and tempo for Canadian women reaching the end of their reproductive life by 2001 . Fertility differences between regions will be examined within the context of equally diversified conjugal history of these cohorts. Then, contraceptive use, with the emphasis put on contraceptive sterilization that also varies by region will be looked at within the path of conjugal history and fertility decisions. 


\section{Data Sources and Approach}

The approach adopted is longitudinal, cohort based, considering fertility as a sequential phenomenon. The arrival of the first, second and third births and the moment of sterilization by age of the woman in a couple, based on retrospective data, will be measured for cohorts who were reaching the end of their reproductive life in 2001, that is women who were aged 40-49 and observed in the 2001 Canadian General Social Survey undertaken by Statistics Canada. The sample includes 2490 women belonging to the cohort, and allows for an analysis of Canada as a whole and five regions: Atlantic, Québec, Ontario, Prairies and British Columbia.

Retrospective data collected on date of contraceptive sterilization are used. Respondents were asked if they themselves or their current spouse had undergone a surgical sterilizing intervention, and if so, was that intervention done for contraceptive or medical purposes, and when did it occur. From this information, for each women living with a spouse at survey, one could estimate the age of the woman when the couple became sterilized, whether the intervention was a tubal ligation or a vasectomy. From this estimate of the women's age when the couple became sterilized, the duration elapsed since the last birth and sterilization was established. The GSS 2001 data allowing to make these estimates was available through the Statistics Canada Data Research Center in Montreal, called the Quebec Inter-University Centre for Social Statistics (QICSS). Life table and Cox analysis of factors related to the choice of sterilization could then be developed. The analysis was based on weighted data and bootstrap weights provided by Statistics Canada were used to estimate the models.

The factors related to the choice of sterilization (Bumpass 2000; Marcil-Gratton and Lapierre-Adamcyk 1989) and the categories defined for the analyses were as follows:

- Regions: Atlantic (Newfoundland, Prince Edward Island, Nova Scotia and New Brunswick), Québec, Ontario, Prairies (Manitoba, Saskatchewan and Alberta) and British Columbia.

- Respondent's number of biological children before current union: no children, one child, 2 children or more.

- $\quad$ Spouse's children before current union: yes, no.

- $\quad$ Couple's common child: yes, no. 
- Respondent's education: high school or less; college-some university; university degree.

- Respondent's religion: no religion, catholic, protestant, other religion.

- Respondent's religiosity: no attendance, some attendance.

- Respondent's birthplace: in Canada; outside Canada.

The information about most socio-economic characteristics was collected on the respondent only, not about the spouse. These cohorts contributed mostly to the fertility of the 1980 and early 1990 s, but period fertility rates and variations will not be analysed, since this was done many times (for example, Ram 2007; Henripin 2003; Bélanger and Ouellet 2001). The emphasis will be on cohort fertility.

\section{Cohort Fertility Variations: Quantum and Tempo}

Before getting into the analysis of contraceptive sterilization, a descriptive presentation of cohort fertility measures will be made. The focus will be on variations within Canada, between 5 regions. Fertility is measured by the total number of biological children born to women aged 40-49 years old during their lifetime, as reported in the 2001 GSS survey for Canada. The average number of children, the distribution of women by parity and the cumulative number of women who reached each parity by age will be used as indicators (Figure 1).

Figure 1 shows that for Canada as a whole, these cohorts had 1.9 children. This average varies between regions: from 1.7 in Québec, the lowest level, to 2.1 in the Prairies, the highest level. The distribution of women by number of children illustrates where meaningful differences are: if the proportions of childless women and of women with exactly 2 children are not very different, the percent of women with only one child varies from 12\% (Prairies) to 23\% (Québec) and the percent of women with 3 or more children is highest in the Prairies (32\%) and lowest in Quebec (19\%). The other regions are close to the Canadian average. However, Québec stands out as having a specific regime with the lowest average number of children, but a more detailed examination of the data leads to a more refined judgment. The cumulative proportion of women reaching at least parity 1,2, or 3 during their lifetime (Figure 2) confirms the differences between Quebec and the other Canadian regions: fewer 


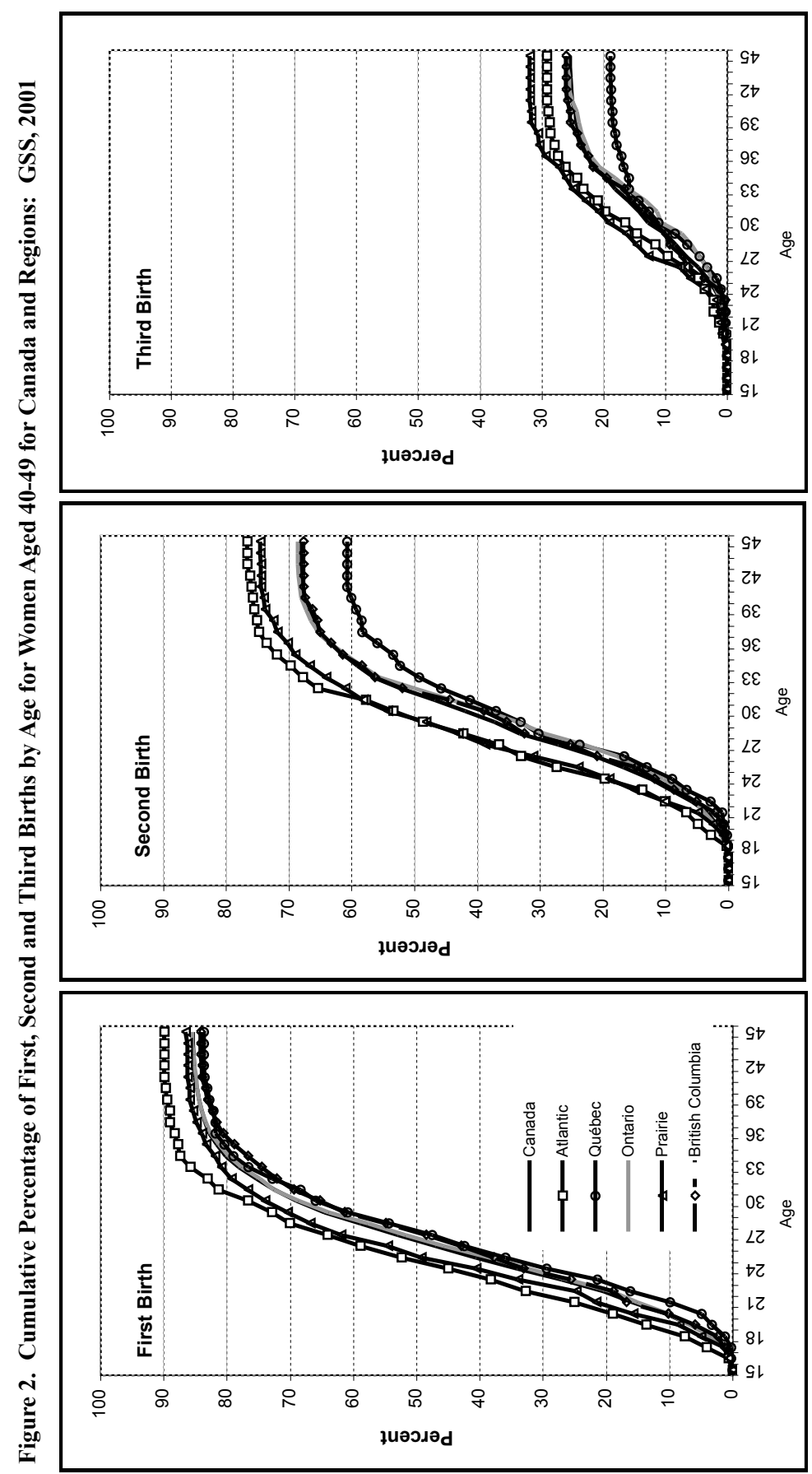

CSP 2010, 37.3-4: $375-410$ 
Quebec women reach each parity, not only are they less likely to have one child, but they also are less likely to have a second, and a third child. But the other regions are not homogeneous. The Atlantic region and the Prairies tend to have a similar pattern; more women are likely to have at least 1,2 , or 3 children than in the rest of the country. On the other hand, Ontario and British Columbia are close together: they respectively are about $68 \%$ to have at least 2 children and around $26 \%$ to have at least 3 . Québec stands out by itself with only $61 \%$ having at least 2 children and less than $20 \%$ having at least 3 . These results show that low fertility can be achieved through different paths.

The slopes of the curves vary, and this can be due to the differences either in fertility quantum or tempo. Since the quantum at 40 varies substantially, especially for the second and third births (Figure 2), median age at birth for each parity was calculated. Table 1 shows that lower median age at first birth in the Atlantic region and the Prairies is associated with their higher percentage who had a first birth. And this pattern also appears for the second and the third births. Ontario and British Columbia women who have a lower fertility tend to have their children one or two year later. But this association is broken in Québec: these women have fewer births, and the curves of Figures 3 and 4 in particular lead to believe that they postpone the coming of their children, but it turns out that they do not, they have fewer children. A child postponed seems to become an unborn child.

\section{Conjugal History Variations}

As the proximate determinants approach has established, marriage or conjugal union is one of the determining factors of fertility level. An indicator of the cohort conjugal history during the reproductive period has been developed based on retrospective data on all conjugal unions. This indicator, called conjugal history, gives an adequate measurement of the conjugal situation reached by respondents at the end of their reproductive life, taking into account unions and separations. It is more meaningful than the usual marital status observed at survey. Five categories were created: never in a union; stable first union for both spouses, no breakup; first union, broken, no second union during reproductive years; second or + union for at least one spouse, union lasting till end of reproductive years; second or + union, broken before end of reproductive life.

Figure 3 presents the distribution of the cohort aged 40-49 for Canada and the regions by conjugal history. The very low percentage of women never in a union may be underestimated since these persons are 


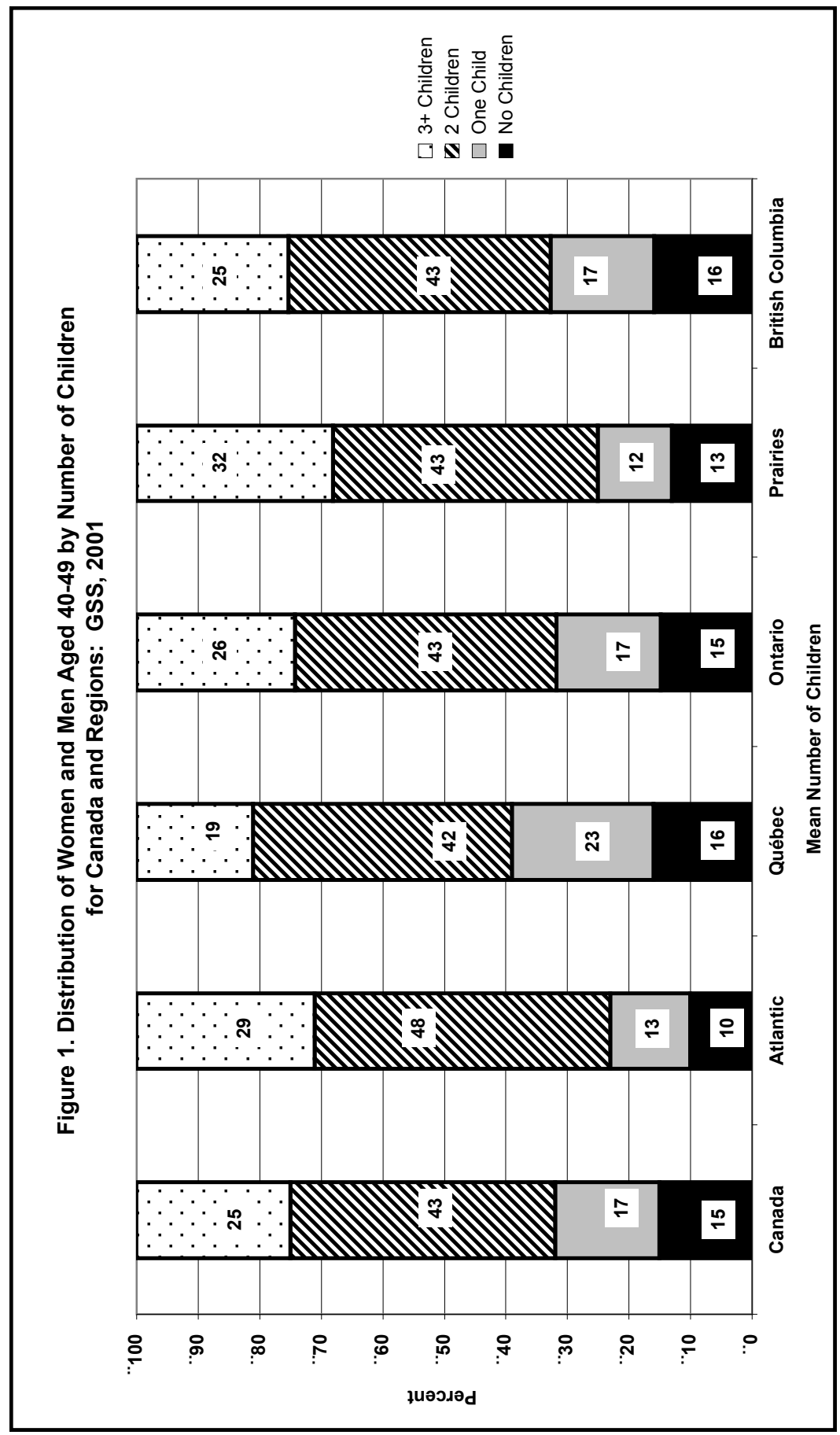

CSP 2010, 37.3-4: $375-410$ 


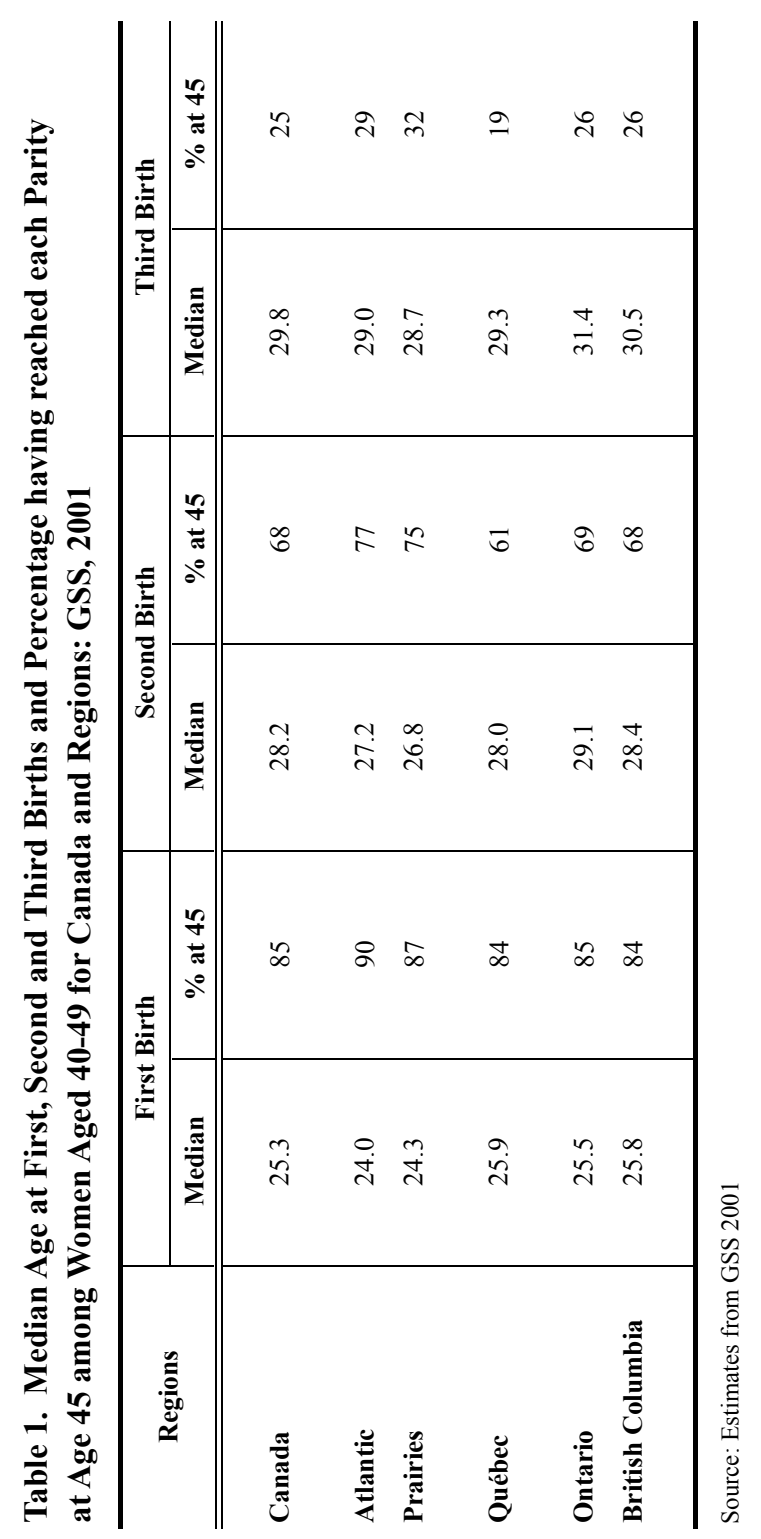

CSP 2010, 37.3-4: $375-410 \quad 384$ 
Low Fertility and Contraceptive Sterilization: The Canadian Case

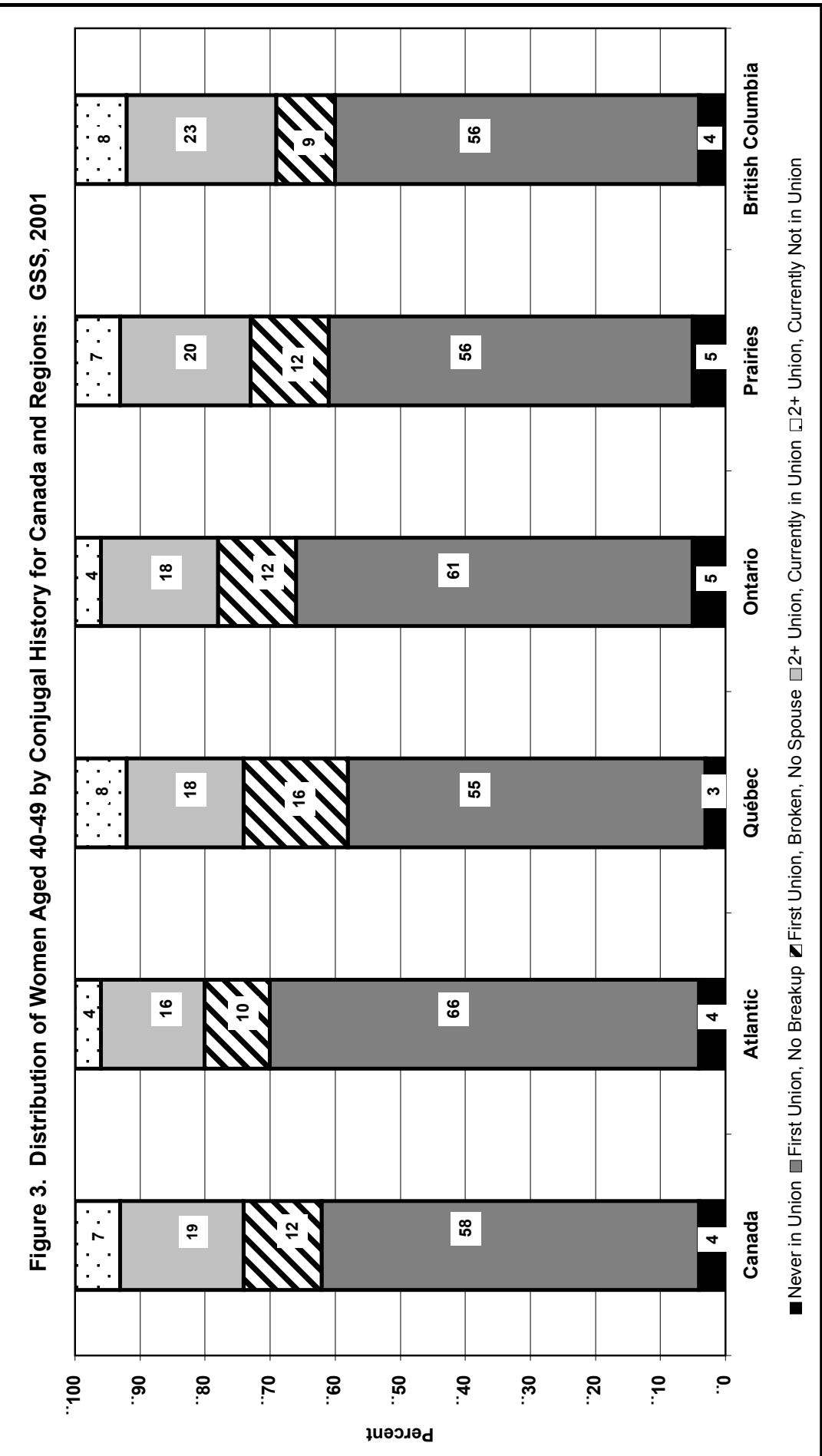

CSP 2010, 37.3-4: $375-410$ 
more likely to live alone, and then tend to be more difficult to reach by surveys. This figure shows that in Canada $58 \%$ of women were still in their first union at end of their reproductive life; this percentage varies from 55\%, lowest in Québec, to $66 \%$ in the Atlantic region. The percentage of women living in their second or + union also varies substantially from $16 \%$ in the Atlantic to $23 \%$ in British Columbia. Some indicators summarizing the data shown in the figure point at a few interesting and relevant similarities and differences in the stability of unions and the attraction of living as a couple (Table 2). Firstly, between Canadian regions, there is a significant difference in the percentage of women not living in a union at the end of their reproductive life; Québec distinguishes itself with $27 \%$ of women living without a spouse $(18 \%$ in the Atlantic region, $21 \%$ in Ontario and $\mathrm{BC}$ and $24 \%$ in Prairies). Secondly, first unions seem to be more stable in the Atlantic region than in others regions with $68 \%$ of unbroken unions among first unions compared to $64 \%$ in Ontario, 59\% in Prairies and 58\% in British Columbia, once more, Québec has the lowest percentage (57\%) although not significantly different.

Table 2

Indicators of Conjugal Stability among Women Aged 40-49 For Canada and Regions: GSS, 2001

\begin{tabular}{lccc}
\hline \multicolumn{1}{c}{ Regions } & $\begin{array}{c}\text { Percent of } \\
\text { Women not in } \\
\text { a Union }\end{array}$ & $\begin{array}{c}\text { Percent of } \\
\text { Unbroken } \\
\text { Unions among } \\
\text { First Unions }\end{array}$ & $\begin{array}{c}\text { Percent of } \\
\text { Women in } \\
\text { Union among } \\
\text { those with a } \\
\text { First Broken } \\
\text { Union }\end{array}$ \\
\hline Canada & 23 & & \\
Atlantic & 18 & 61 & 51 \\
Québec & 27 & 68 & 54 \\
Ontario & 21 & 57 & 44 \\
Prairies & 24 & 64 & 52 \\
British Columbia & 21 & 59 & 52 \\
& & 58 & 57 \\
\hline
\end{tabular}

Source: Estimates by authors from Statistics Canada, GSS, 2001 
Finally, and this indicator is particularly relevant when looking at fertility differentials, the percentage of women in a union among those who broke their first union is lower in Québec than in other Canadian regions ( $44 \%$ versus $57 \%$ for British Columbia; $54 \%$ for Atlantic region and $52 \%$ for Ontario and Prairies). In summary, Quebec women show a lower degree of attraction for living as a couple and for conjugal stability than for women in other Canadian regions, both features being less favourable to fertility. Periods without a spouse during the reproductive years may indeed have an impact on lifetime fertility levels.

\section{Relationship between Conjugal History and Fertility}

Instead of using the mean number of children, parity progression ratios are used to examine the link between fertility and the conjugal history, focusing on the second $\left(a_{1}\right)$ and third $\left(a_{2}\right)$ births, since the variations between proportions having a first birth are small. Figure 4 presents the parity progression ratio, $\mathrm{a}_{1}$, for women by conjugal history regrouped in two categories: those in a stable first union, and those with a more complex conjugal history; the probability $\mathrm{a}_{1}$, to have a second child among those who had a first one, is measured by the duration elapsed since the preceding birth (life table estimates).

Quite systematically, $a_{1}$ is higher for women in a stable first union than for those with a complex conjugal history. This means that a stable first union was a more favourable environment to decide to have a second child. During the first five years following the first birth, differences between regions are not very important, the curves crossing one another, but during the following years, women in a stable first union throughout their reproductive life were more likely to have a second child than those who had a marital break-up; and this is true in all Canadian regions. Ten years after the first birth, Table 3 shows that the difference between the two groups is still high and the ratio varies from 1,16 to 1,27 in the various regions. The levels of $\mathrm{a}_{1}$ also varies quite substantially across regions; at duration 10, when compared with Québec, the lowest level, $a_{1}$ is 6 to $15 \%$ higher in other regions among women in stable first unions. On the other hand, for women with a marital break up, deeper differences appear: $a_{1}$ could be from $15 \%$ to $25 \%$ higher in other regions than in Québec. 
Table 3

Parity Progression Ratios, $a_{1}$ and $a_{2}$, and Indicators of Relative Differences among Regions compared with Québec and between Conjugal Hiistory Categories

for Canada and Regions: GSS, 2001

\begin{tabular}{|c|c|c|c|c|c|c|}
\hline & Canada & Atlantic & Québec & Ontario & Prairies & BC \\
\hline & \multicolumn{6}{|c|}{ Parity Progression Ratio $a_{1}$} \\
\hline \multicolumn{7}{|c|}{ Women still in their first union at time of survey } \\
\hline$a_{1}$ & 0.834 & 0.881 & 0.779 & 0.827 & 0.896 & 0.845 \\
\hline Québec $=100$ & 107 & 113 & 100 & 106 & 115 & 109 \\
\hline \multicolumn{7}{|c|}{ Women with other conjugal statuses } \\
\hline $\mathrm{a}_{1}$ & 0.691 & 0.736 & 0.613 & 0.694 & 0.770 & 0.711 \\
\hline Québec $=100$ & 113 & 120 & 100 & 113 & 125 & 116 \\
\hline \multicolumn{7}{|c|}{ Women still in their first union at time of survey/Women with other conjugal statuses } \\
\hline & 1.21 & 1.20 & 1.27 & 1.19 & 1.16 & 1.19 \\
\hline & \multicolumn{6}{|c|}{ Parity Progression Ratio $a_{2}$} \\
\hline \multicolumn{7}{|c|}{ Women still in their first union at time of survey } \\
\hline $\mathrm{a}_{2}$ & 0.359 & 0.372 & 0.312 & 0.372 & 0.396 & 0.335 \\
\hline Québec $=100$ & 115 & 119 & 100 & 119 & 127 & 107 \\
\hline \multicolumn{7}{|c|}{ Women with other conjugal statuses } \\
\hline $\mathrm{a}_{2}$ & 0.409 & 0.419 & 0.322 & 0.416 & 0.441 & 0.483 \\
\hline Québec $=100$ & 127 & 130 & 100 & 129 & 137 & 150 \\
\hline \multicolumn{7}{|c|}{ Women still in their first union at time of survey/Women with other conjugal statuses } \\
\hline & 0.88 & 0.89 & 0.97 & 0.89 & 0.90 & 0.69 \\
\hline
\end{tabular}

Source: Estimates by authors from Statistics Canada, General Social Survey 2001 


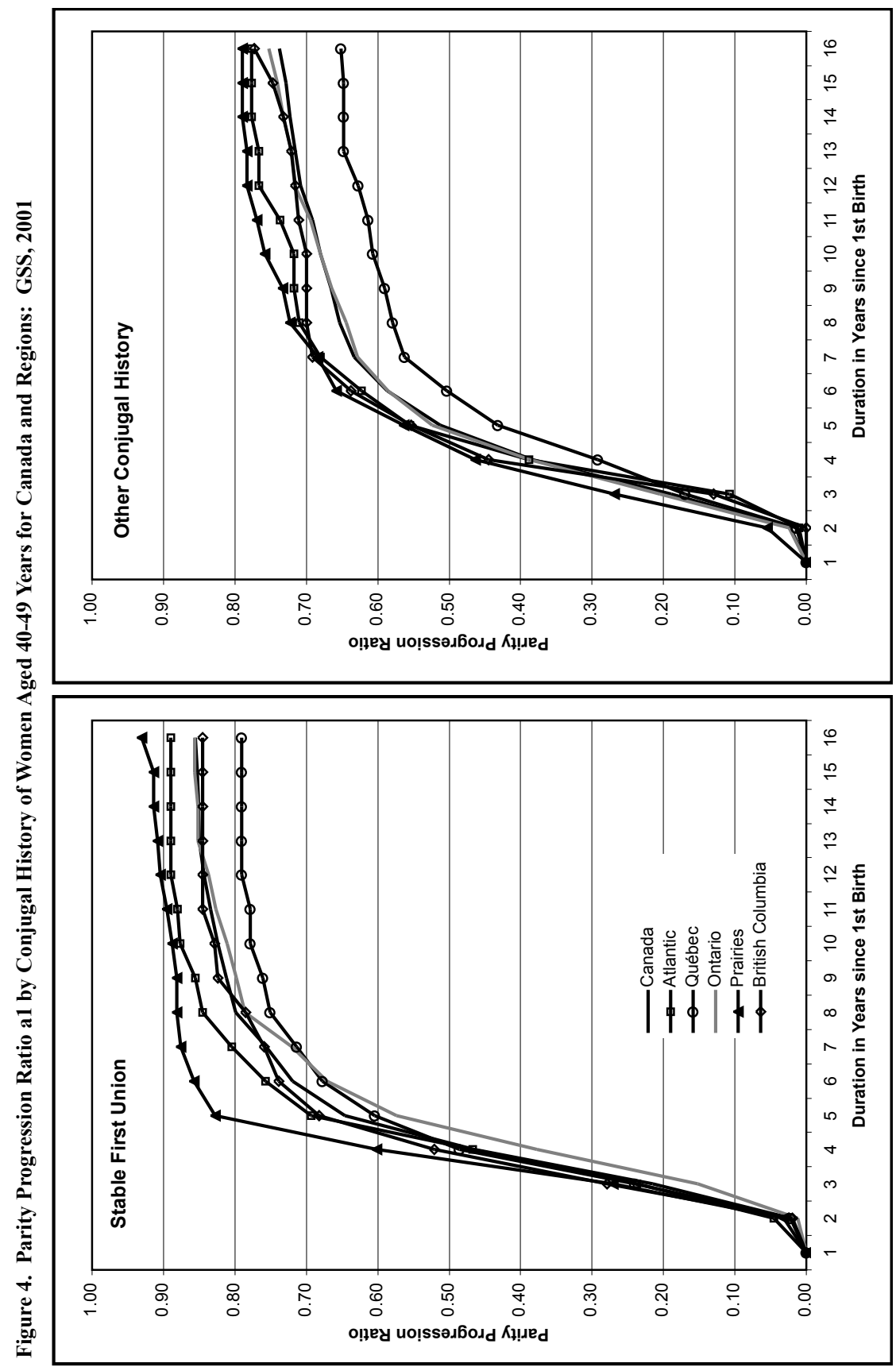


The parity progression ratio $\mathrm{a}_{2}$ leads to reverse results. Figure 5 shows that women with a marital breakup who had a second child, were more likely to have a third birth than those in a stable first union, except in Québec. Québec presents again the lowest $a_{2}$ for both groups of women (Figure 5 and Table 3); for those in a stable first union, in other regions $\mathrm{a}_{2}$ is higher by $7 \%$ to $27 \%$ when compared with Québec; for those with a marital breakup, the differences are even greater, varying from $29 \%$ to $50 \%$. Moreover, in Table 3, we see that the relationship between the two groups has been reversed: women in stable first unions were less likely to have a third birth than their counterparts after 10 years (differences varies from $10 \%$ to $31 \%$ depending on the region, except in Québec where it is almost equal), while as we have seen they were more likely to have a second child $\left(\mathrm{a}_{1}\right)$.

These results suggest that couples who stay together during their reproductive life are more likely to settle for a two child family, while women who change partner are more likely, if they already have two children, to decide to have another one with a new partner. This will be particularly relevant while analyzing the choice of contraceptive means. The choice of a non reversible method could be a barrier to have a third child, if that choice is made too early as is suggested by the literature (Chapel Hill Tubal Reversal Center 2009; Marcil-Gratton 1988; Nervo et al. 2000; Worcester 2003). Let us now turn to contraceptive behaviour.

\section{Contraception Use in Canada}

Access to effective contraceptive methods has spread into Canada in the early 1970's (Act 1969) (Liu and Fisher 2002). The different methods existing today to prevent a pregnancy can be classified into two main groups: a) reversible methods such as traditional methods like the rhythm method (Ogino-Knaus), temperature, or Billings method, but also the pill, IUD, condom, and b) irreversible methods such as female (tubal ligation) and male sterilization (vasectomy).

According to data from the 2001 GSS Survey, in all Canadian regions, the majority of women aged 40-49 were using a contraception method at the end of their reproductive life (Figure 6). The percentage of women who used a reversible method is $11 \%$ for Canada as a whole and varies from $8 \%$ in the Prairies to $13 \%$ in British Columbia. Contraceptive sterilization is the leading method of regulating fertility among these women: in Canada, 26\% were sterilized themselves and $22 \%$ lived with a man who had a vasectomy. In total, 48 percent of these women were protected by a sterilization to which we can add 14 percent who were sterilized for medical reasons.

CSP 2010, 37.3-4: $375-410$ 


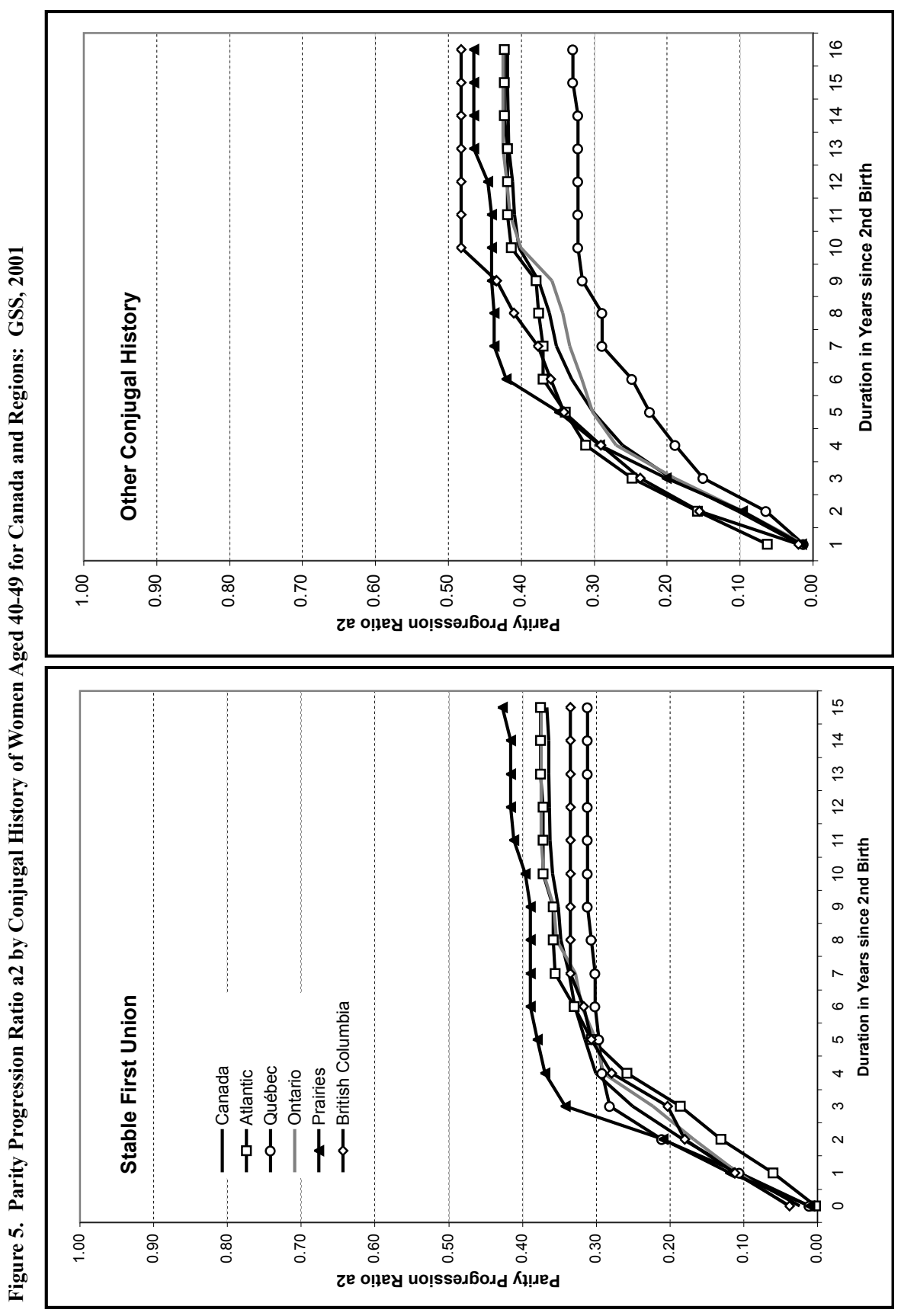

CSP 2010, 37.3-4: $375-410$ 391 


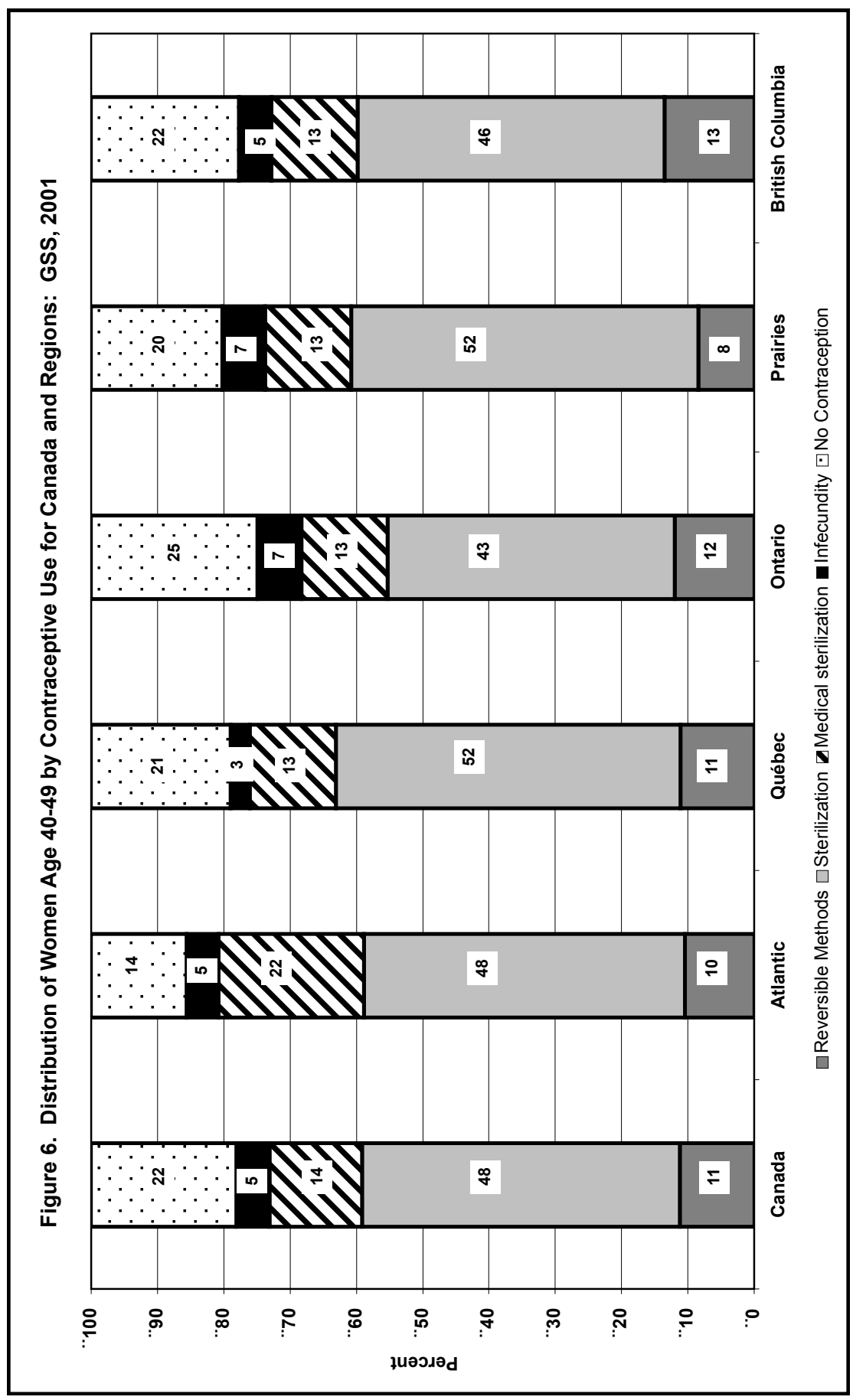

CSP 2010, 37.3-4: $375-410$ 
Among the different regions, contraceptive sterilization level varies between $43 \%$ in Ontario (22\% of women and $21 \%$ of men), $46 \%$ in the $\mathrm{BC}(23 \%$ of women and men), $48 \%$ in Atlantic region $(25 \%$ of women and $23 \%$ of men) and $52 \%$ in Québec (31\% of women and $21 \%$ of men) and in the Prairies (27\% of women and $25 \%$ of men).

Among women aged 40-49 living in a union, at least one woman out of two was sterilized or lived with a sterilized man. This proportion varies by region from $50 \%$ in Ontario to $59 \%$ in Quebec (Figure 7). In most regions, women who lived in a sterilized couple are protected by the sterilization of their partner slightly more often than by their own, (in Atlantic, $28 \%$ for men vs. $25 \%$ for women; in Ontario, $27 \%$ vs. $23 \%$; in the Prairies, $33 \%$ vs. $29 \%$; and in BC, $29 \%$ vs. $22 \%$ ) except in Québec, where the proportion is almost identical (among women in sterilized couples, $30 \%$ of women are sterilized against $29 \%$ of men). Among women who reported living outside a union at the end of their reproductive life, the contrast is most vivid between Ontario, where one out of five women is sterilized, and Québec where it is one out of three; the other regions are in between these two extremes: one out of four in Atlantic region $(25 \%)$ and the Prairies $(24 \%)$ and British Columbia (29\%).

Among women living in a union, we observe that the proportion of sterilized couples increases with the number of children ${ }^{1}$ (Figure 8). In Quebec and the Prairies, more than half of the couples with one child are protected by sterilization. The proportion of sterilized couples varies from $53 \%$ in Quebec to $36 \%$ in Ontario. More frequently, it is a male sterilization, except for Atlantic region and $\mathrm{BC}$ where the proportion of tubal ligation is higher than $50 \%$. Whatever the region, among couples having two children, more than one out of two are being protected from pregnancy by sterilization and most often by vasectomy. For these couples, the sterilization rate varies from $63 \%$ in Quebec to $53 \%$ in BC. For couples with 3 children or more, the picture is slightly different: more than three couples out of four in Quebec (78\%) and the Prairies $(76 \%)$ are protected from risk of pregnancy by an irreversible method, and for these two regions respectively, nearly three out of five and one out of two by tubal ligation.

Whatever the number of children, the proportion of women belonging to a sterilized couple is always higher in Quebec compared with other Canadian regions. As we have previously noted, women in Quebec are more likely to have had a broken first union than their Canadian compatriots, and their likelihood of having a second or third child is weaker when they are not in their first union (Figure 4). Can we suppose that Québec couples who are separated after the birth of one or more children were more likely to be protected from a pregnancy risk by

CSP 2010, 37.3-4: $375-410$ 


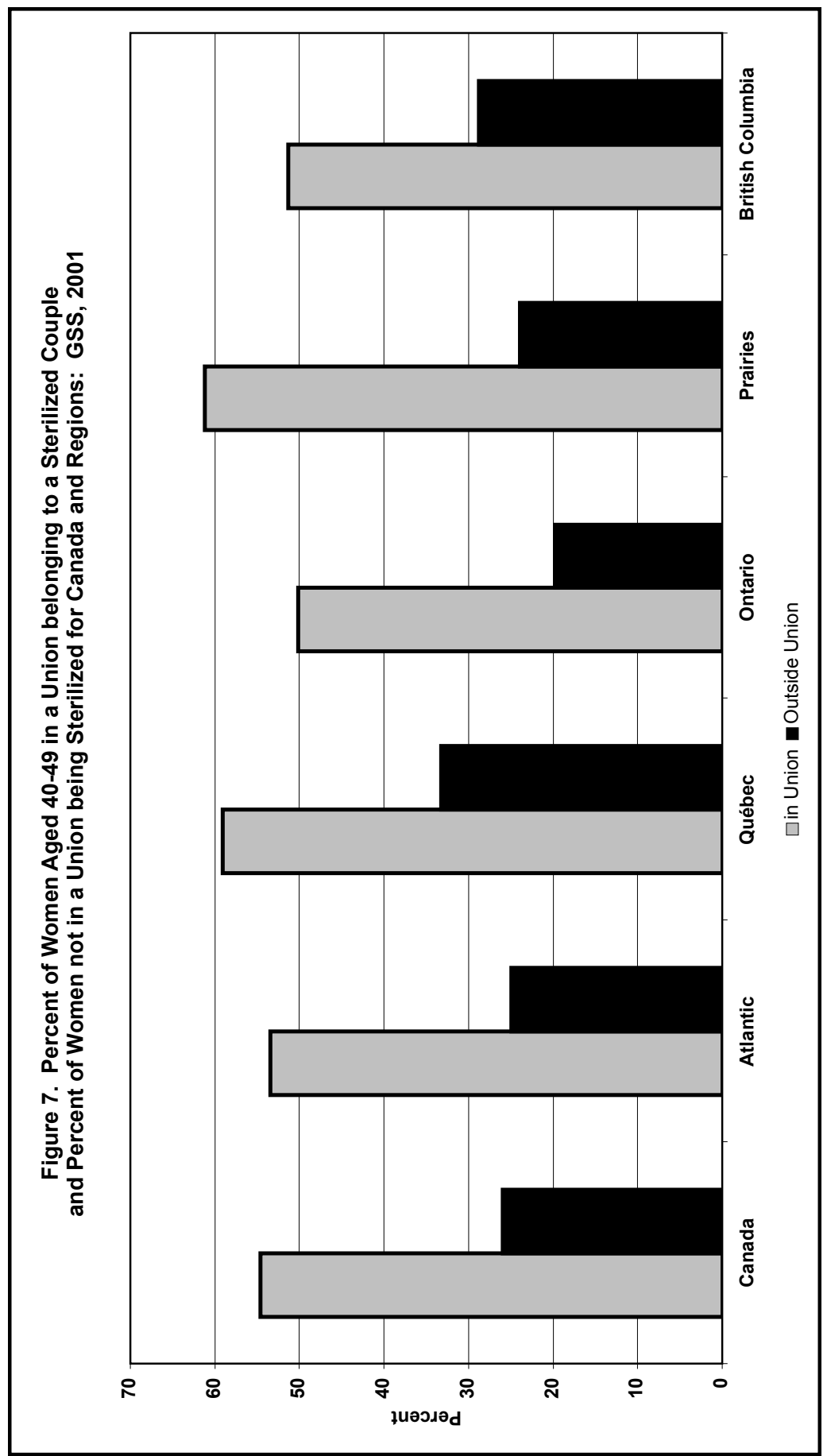

CSP 2010, 37.3-4: $375-410$ 


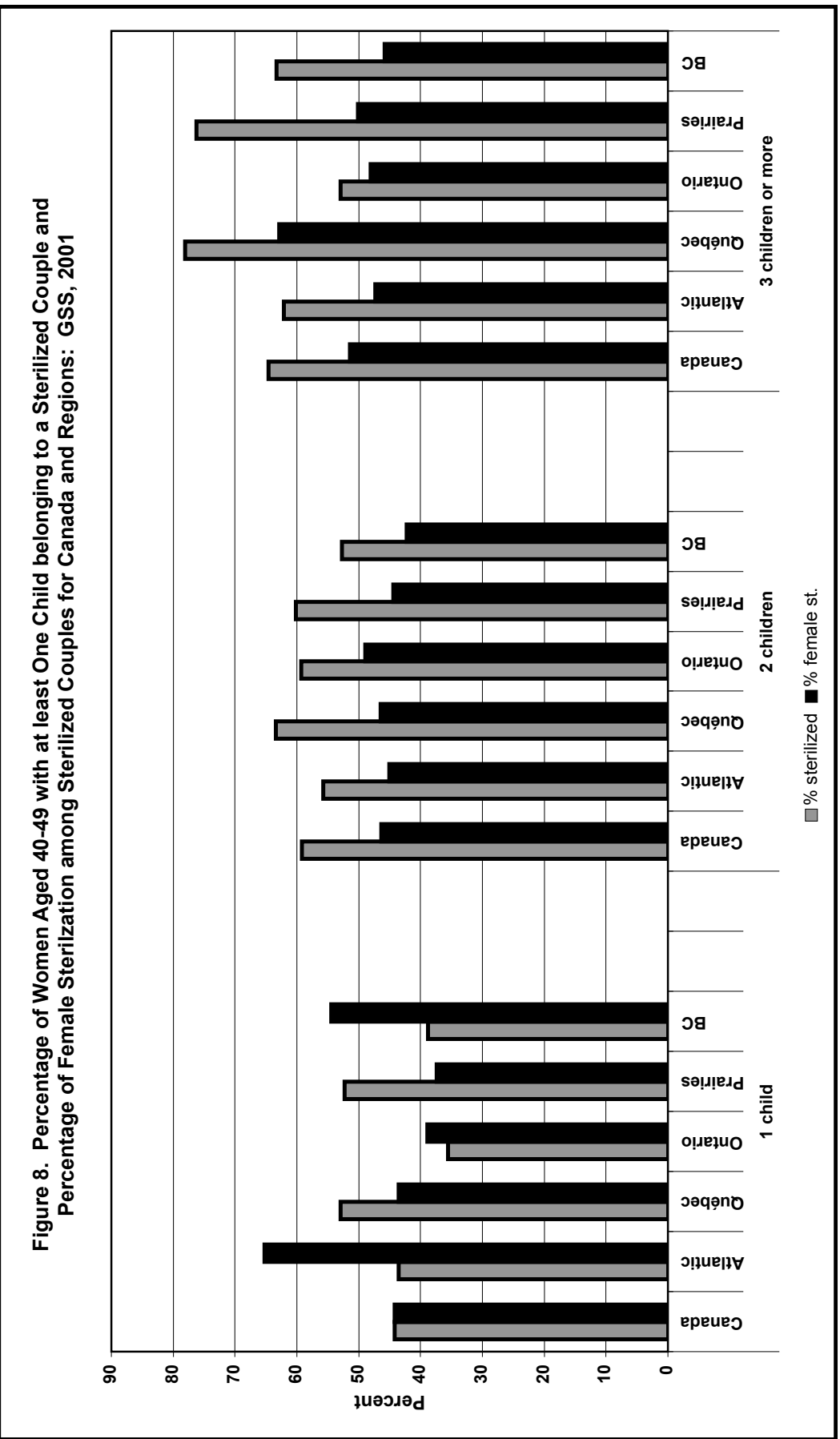


sterilization, or that a sterilization could have occurred after the separation? If so, this situation would reduce the possibility of having a new child in a new union. Data from Table 4 show that the majority of sterilized women by tubal ligation have undergone this intervention within an union, and most often during the first union: this proportion varies from $59 \%$ in $\mathrm{BC}, 67 \%$ in Quebec, 69\% in Ontario, $70 \%$ in the Prairies and $75 \%$ in Atlantic. The proportion of women sterilized before the first marriage is relatively low. It varies between $1 \%$ in $\mathrm{BC}$ and $4 \%$ in other areas, it is likely that these sterilizations occurred for medical reasons. Whereas in Quebec, first unions are "fragile" and going in a new union is less frequent than in other Canadian regions, there is also a slightly higher proportion of sterilization after the first union than elsewhere: $13 \%$ against $11 \%$ in $\mathrm{BC}, 10 \%$ in Ontario, $8 \%$ in the Prairies and $7 \%$ in Atlantic. Women in Québec tend to reduce more than elsewhere in Canada their ability to have a birth with a new partner.

\section{Paths leading to Contraceptive Sterilization}

We already looked at fertility levels, conjugal history and contraceptive use in the Canadian regions and have shown the diverse ways that women reached their fertility projects. This section is devoted to examine more closely the factors leading to the choice of contraceptive sterilization for couples, verifying at the same time the persistence of regional differences, once a number of relevant factors are controlled for. For two groups, the retrospective survey data provide all the information needed. These groups are: couples in a stable first union (first union for both spouses) at the end of the reproductive period; couples with at least one spouse in a second union or more at the end of the reproductive period. We have already seen that these two groups differ in the way they are likely to have a second or a third child. We will now examine the paths that lead them to contraceptive sterilization.

The probability of belonging to a sterilized couple at the end of the reproductive period was established by the means of a life table by exact age of the women at the time the couple underwent sterilization, either male or female. In Canada, as can be seen in Table 5, the probability of belonging to a sterilized couple at 50 is $66 \%$ for those couples in a stable first union and slightly higher for those where one spouse at least is in a second or higher order union $(72 \%)$. These percentages vary by regions: they are higher in the Atlantic region (81 and 84), in Québec (76 and 75) and in the Prairies (72 and 75); they are substantially lower in Ontario (57 and 67) and BC (59 and 71), especially for couples in a stable first union.

CSP 2010, 37.3-4: $375-410$ 


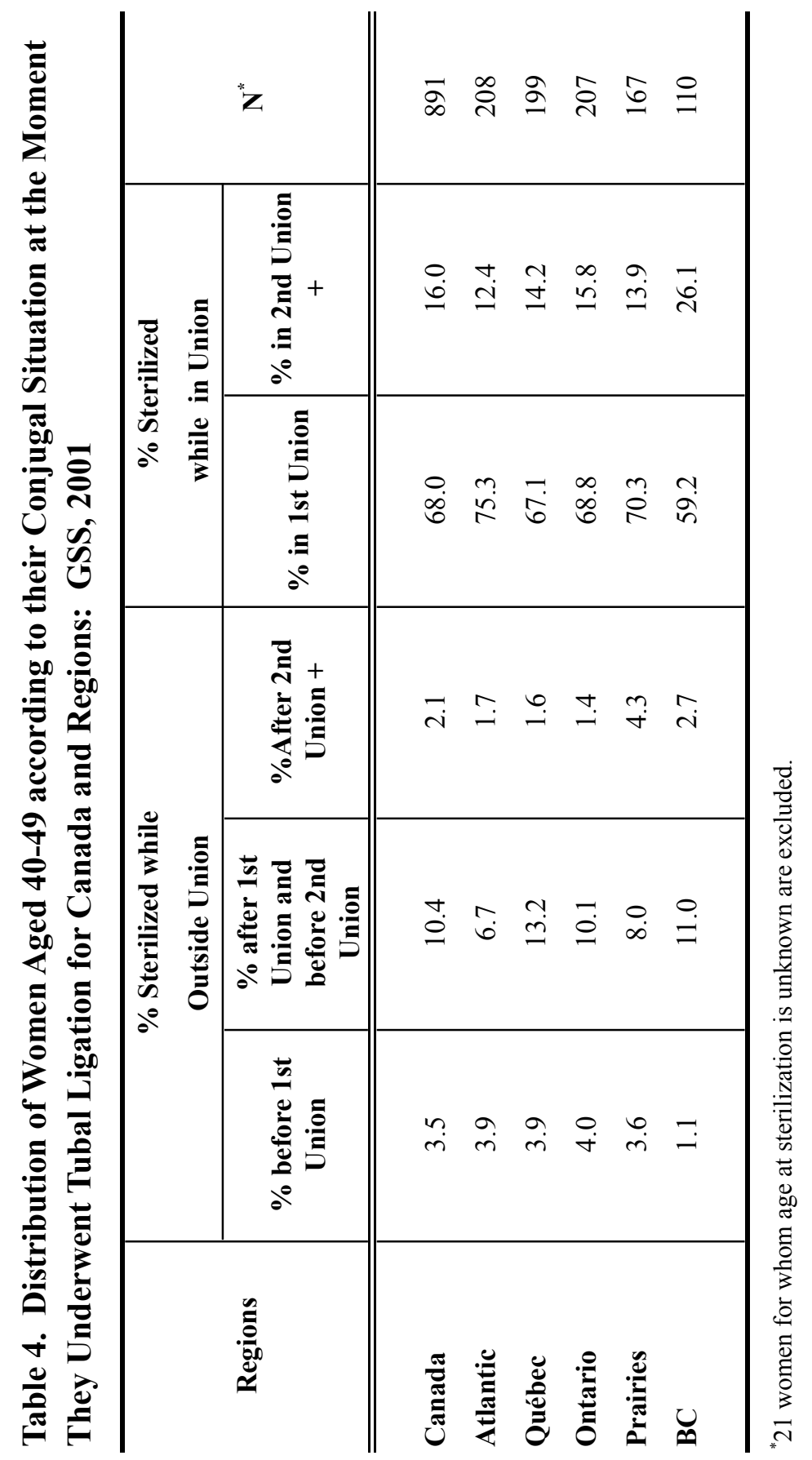


Among women in couples with at least one spouse in a second union+, more than one out of five had already been sterilized at the beginning of the union. The lowest proportions are found in Atlantic $(21 \%)$ and $\mathrm{BC}(22 \%)$ and the highest in the Prairies $(30 \%)$ and Quebec $(28 \%)$. Ontario takes a middle position with one out of four women sterilized at the beginning of the union.

Among women belonging to a sterilized couple, the average number of children varies for women still in their first union between 2.5 in Prairies and 2.2 in BC and Québec, and for women in a couple where at least one spouse isin a second or higher union, between 2.1 in Atlantic and 1.6 in Québec (Table 5). Thus, in Québec the average number of children per sterilized couples for both types of unions is the lowest among all Canadian regions.

\section{Contraceptive Sterilization Among Couples in a Stable First Union}

Is the decision to become sterilized taken early in the reproductive life? Very few choose to be sterilized among childless persons. Among couples in stable first unions who had at least one birth (Table 6), the probability to recourse to sterilization right after the last birth, 28\% for Canada as a whole, varies from 39\% in the Atlantic region (Prairies are close at 33\%) to $24 \%$ in Ontario (Québec and British Columbia are quite close to this level). These are likely to be couples who are quite sure about not wanting another child, although some previous research has shown that this is a moment susceptible to lead to regret, in particular for women sterilized before age 30 (Marcil-Gratton 1988). As time goes by (10 years after the last birth), the differences become more crystallized: a little over 70\% in Atlantic, in Québec and in the Prairie, compared to only $56 \%$ in Ontario and $\mathrm{BC}$. The percentages continue to grow as duration since last birth increases, but the differences between regions resist.

Among sterilized couples in stable first unions who have at least one child, the women's average age at sterilization of the couple (by male or/and female sterilization) varies between 32.4 in the Prairies and 33.7 years old in Ontario (Table 6).

Are these variations related to specific features of each region and will they persist after controlling for relevant factors? A Cox regression analysis was used to examine the factors that may be related to the couple's decision to become sterilized as the duration since the last birth increases (Table 7, left part). Since the duration since the last birth was 


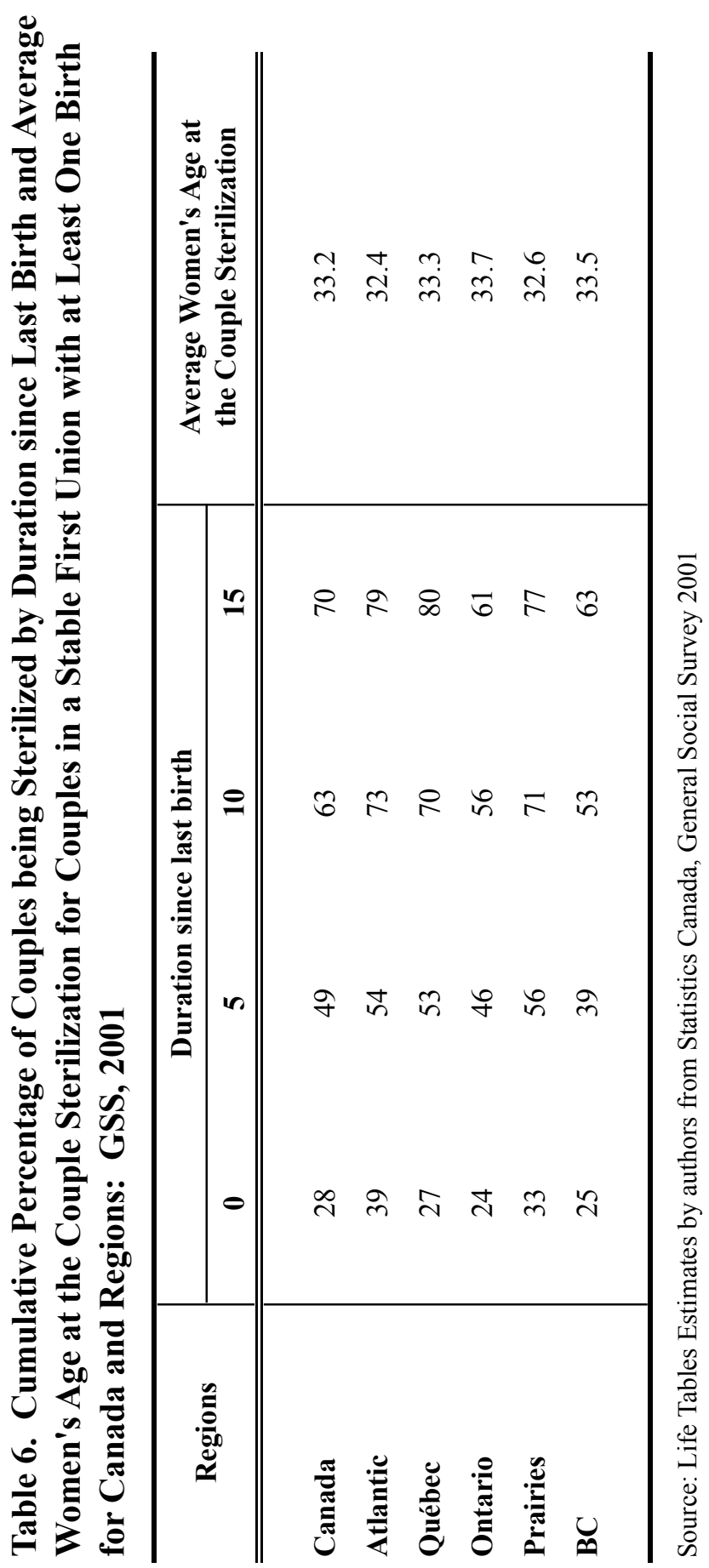


Table 7

Effects of Various Factors on the Probability of belonging to a Sterilized Couple

for Stable First Unions with at least One Child and for Couples with at least One Spouse

in a 2nd+ Union and on the Probability of having a Common Child in a "Second Union +", Women Aged 40-49 at Time of Survey for Canada and Regions: GSS, 2001

\begin{tabular}{|c|c|c|c|c|c|c|c|c|c|}
\hline \multirow{3}{*}{ Factors } & \multirow{3}{*}{\multicolumn{2}{|c|}{$\begin{array}{c}\text { Stable First Unions } \\
\text { with at least One } \\
\text { Child }\end{array}$}} & \multirow{3}{*}{ Factors } & \multicolumn{6}{|c|}{ Couples with at least One Spouse in a $2^{\text {nd }}+$ Union } \\
\hline & & & & \multirow{2}{*}{\multicolumn{2}{|c|}{$\begin{array}{l}\text { Probability of } \\
\text { Sterilization }\end{array}$}} & \multicolumn{4}{|c|}{ Probability of having a Common Child } \\
\hline & & & & & & \multicolumn{2}{|c|}{$\begin{array}{c}\text { Sterilized Couples } \\
\text { Included }\end{array}$} & \multicolumn{2}{|c|}{$\begin{array}{l}\text { Sterilized Couples } \\
\text { Censored }\end{array}$} \\
\hline \multicolumn{3}{|c|}{ Canadian Regions (Québec) } & \multicolumn{7}{|c|}{ Canadian Regions (Québec) } \\
\hline Atlantic & 0.928 & $* *$ & Atlantic & 1.119 & & 1.675 & $* * * *$ & 1.658 & $* * * *$ \\
\hline Ontario & 0.878 & $* * * *$ & Ontario & 0.997 & & 1.005 & & 0.964 & \\
\hline Prairie & 1.019 & & Prairie & 1.156 & $* *$ & 1.573 & $* * * *$ & 1.646 & **** \\
\hline BC & 0.855 & ***** & B.C. & 0.987 & & 1.825 & $* * * *$ & 1.638 & ***** \\
\hline \multicolumn{3}{|c|}{$\begin{array}{l}\text { Number of Biological Children } \\
\text { (2 Children) }\end{array}$} & \multicolumn{7}{|c|}{ Respondent's Number of Children before Current Union (No Children) } \\
\hline One child & 0.570 & ${ }^{* * * * *}$ & One child & 2.056 & ***** & 0.729 & ***** & 1.077 & \\
\hline 3 children + & 1.386 & ***** & 2 children + & 5.188 & $* * * *$ & 0.188 & ***** & 0.497 & $* * * *$ \\
\hline \multicolumn{3}{|c|}{ Woman's Age at Last Child (25-29) } & \multicolumn{7}{|c|}{ Spouse has Children before Current Union (No Children) } \\
\hline Less than 25 & 0.979 & & Had children & 1.547 & ***** & 0.632 & ***** & 0.909 & **** \\
\hline $30-34$ & 0.998 & & \multicolumn{7}{|c|}{ Couple's Common Child (No) } \\
\hline 35 and over & 1.121 & ***** & Yes & 6.535 & ***** & & & & \\
\hline \multicolumn{3}{|c|}{$\begin{array}{l}\text { Respondent's Education } \\
\text { (University Degree) }\end{array}$} & \multicolumn{7}{|c|}{ Respondent's Education (University Degree) } \\
\hline \begin{tabular}{l|l} 
College-Some \\
University
\end{tabular} & 1.503 & $* * * *$ & $\begin{array}{c}\text { College-Some } \\
\text { University }\end{array}$ & 0.883 & $* * *$ & 1.665 & ***** & 1.764 & **** \\
\hline $\begin{array}{l}\text { High School or } \\
\text { less }\end{array}$ & 1.171 & $* * * *$ & $\begin{array}{c}\text { High School or } \\
\text { less }\end{array}$ & 0.922 & & 1.467 & $* * * *$ & 1.490 & $* * * *$ \\
\hline \multicolumn{3}{|c|}{ Respondent's Religion (Catholics) } & \multicolumn{7}{|c|}{ Respondent's Religion (Catholics) } \\
\hline No religion & 0.878 & *** & No religion & 1.069 & & 0.583 & ***** & 0.558 & $* * * *$ \\
\hline Protestant & 0.983 & & Protestant & 1.006 & & 1.108 & **** & 1.003 & \\
\hline Other religion & 0.565 & $* * * *$ & Other religion & 0.330 & $* * * *$ & 0.971 & & 0.894 & \\
\hline \multicolumn{3}{|c|}{ Respondent's Religiosity (No) } & \multicolumn{7}{|c|}{ Respondent's Religiosity (No) } \\
\hline Some attendance & 0.863 & $* * * *$ & Some attendance & 0.862 & $* * *$ & 0.844 & $* * *$ & 0.934 & * \\
\hline \multicolumn{3}{|c|}{$\begin{array}{l}\text { Respondent's Birthplace } \\
\text { (Outside Canada) }\end{array}$} & \multicolumn{7}{|c|}{ Respondent's Birthplace (Outside Canada) } \\
\hline In Canada & 2.811 & $* * * *$ & In Canada & 1.683 & $* * * *$ & 0.593 & $* * * *$ & 0.692 & $* * * *$ \\
\hline Number of cases & 893 & & Number of cases & 531 & & 531 & & 388 & \\
\hline & & & & & & & & & \\
\hline
\end{tabular}

Source: Life Tables Estimates by authors from Statistics Canada, General Social Survey 2001

Significance: $* * * *=0.0001 ; * * *=0.001 ; * *=0.01 ; *=0.05$

Note: Relative risks estimated from a Cox regression model; reference category in parentheses; bootstrap weights applied. 
the time variable in the regression, only couples in first stable unions having at least one child were retained in the analysis.

As we have seen earlier, fertility levels, although low in every region, varies significantly. Henceforth, the number of children and the women's age at last birth are the main factors that have to be controlled for, to verify if regional differences in contraceptive sterilization use are significant. Moreover some socio-economic characteristics, all relevant to reproductive behaviour, are also introduced: woman's education, religion and religiosity as well as birthplace. Unfortunately, characteristics of the spouse, which are also relevant, were not available in the survey. Results show that significant differences among regions persist: compared with Québec, the probability of belonging to a sterilized couple tend to be significantly lower in the Atlantic region, in Ontario and B.C.; the differences are not large, not more than $15 \%$, but significant. On the other hand, large and highly significant differences are tied to the number of children (let us remember that only couples with at least one child were included): compared with those who had exactly 2 children, couples who had only one child were much less likely to recourse to sterilization while those who had 3 or more children had much a higher chance of choosing sterilization.

Fertility tempo, measured by the women's age at last birth, shows a significantly higher chance to become sterilized for women reaching their desired number of children after 35 . As far as socioeconomic factors are concerned, education, religion and birthplace have a significant impact while religiosity has a weak effect. Compared with women with university degree, the less educated categories are more likely to belong to a sterilized couple. Compared with Catholics, those who report "other religion" than protestant are much less likely to choose sterilization. Church attendance reduces the likelihood of that choice, but the effect is not strong. Finally, Canadian born are at least twice more likely to become sterilized than those born outside Canada.

Among all the factors considered, having 3 or more children, not having a university degree, being born in Canada, are the categories associated with a strong and significant probability of choosing sterilization as a means of contraception. By contrast, having only one child, having "another" religion than Catholicism or Protestantism are characteristics tied to a significantly lower probability of being sterilized. Regional differences between Québec and the other regions are relatively small; however, they remain significant when socio-demographic factors are taken into account; how to explain this fact? One can speculate that Québec with its particular cultural evolution in the last decades has adopted family attitudes, values and behaviour leading more couples to choose an irreversible method of contraception. The long lasting 
resistance to adopt contraception throughout the six first decades of the Twentietth century was broken with the collapse of the influence of the Catholic Church in the 1960's, and from then on, Quebecers used modern contraception, becoming leaders in the use of the pill before the first birth among women married in the 1970s, and joining other regions in the recourse to contraceptive sterilization (Marcil-Gratton and Lapierre-Adamcyk 1989). But the differences observed here, although persistent, remain small, at least among stable first unions

\section{Contraceptive Sterilization among Couples in a $2^{\text {nd }}$ union+}

Let us now turn to couples who had a more complex conjugal history. In order to analyse their contraceptive behaviour, data are available only for those individuals living in a union at the end of their reproductive life; those who were not in a union at that moment were excluded from this analysis.

Table 8 presents the percentage of these couples in a $2^{\text {nd }}$ union+ who were already sterilized at the beginning of their union. This percentage was higher in Québec and in the Prairies, and lower in B.C. and the Atlantic region, with Ontario close to the national average. Those who were sterilized at the beginning of the union made this decision while being with another spouse and under other circumstances; they then were censored at duration 0 .

Table 7 (right part) presents the results of a Cox regression model for this sub-group of couples. In this case, the time variable was the duration since the union ongoing at the end of the reproductive life. Contrary to stable first unions, couples in "a $2^{\text {nd }}$ union + " show no significant differences when compared with Québec, except for the Prairies, in their likelihood of choosing contraceptive sterilization. Their choice of undergoing sterilization was mostly determined by their fertility, previous to the union or within the higher order union. Couples where women had 2 children or more before the union were 5 times more likely to decide to be sterilized than those where the woman was childless at the time of union; the probability was twice as high for women with 1 child. The fact that the spouse of these women had children before was also a factor leading to a higher probability to decide to be sterilized. But the most important element was the birth of a common child to the couple: compared to those who did not have a common child, the probability was multiplied by 6 . Among the socioeconomic characteristics, some categories are significantly related to choosing sterilization: women reporting a religious affiliation other than Catholic or Protestant are much less likely to choose sterilization; this 
was also the case for those who reported some religious attendance; on the contrary, Canadian born women are significantly more likely to do so when compared with foreign-born. Regional differences between Quebec and the other regions do not resist the effect of fertility which remains the determining factor.

\section{Couples in a $2^{\text {nd }}+$ union at the end of the reproductive life and the arrival of a child}

Did couples in "a $2^{\text {nd }}$ union+" give birth to a child in such unions? For Canada as a whole (Table 8 ), $42 \%$ of those couples have a common child. If couples already sterilized at the beginning of the union are excluded, the percentage is 59\%. Important differences appear between regions, Quebec and Ontario couples showing a lower percentage of common child born in such unions. Do these differences hold when other factors are controlled for. Using a Cox regression model (Table 7, model including all respondents), the probability of having a child in a union where at least one member is in his second + union vary by regions in Canada; compared with Québec, Ontario is not significantly different, but for the other regions, the chance to have such a child is $60 \%-80 \%$ higher than Québec. Other factors are also influential. When the women had two biological children or more at the time of the union compared to women who did not have a biological child, the probability to have another child is reduced by around $80 \%$ (highly significant). Moreover, when the spouse had children at the time of the union, there is a significant $37 \%$ reduction when compared to those where the spouse did not have children. Compared to women with a university degree, less educated women have a higher probability (a significant increase of 47$67 \%$ ) to have a common child with their new partner. When religion is taken into account, only those who do not declare a religion have a lower probability (a reduction of $42 \%$ ) to have a child when compared to Catholics. Religious practice has a weaker negative effect while women born in Canada show a lower probability by $40 \%$ to have a child in such unions compared to foreign born women.

The preceding results are based on all couples in "a second union+", regardless of contraceptive sterilization. Does contraceptive sterilization play a role in the differences that were observed? When introduced in the model (Table 7, model censoring at sterilization), the differences tend to stay in the same direction, but are reduced, for example, the difference between Québec and BC remains significant but the increase is smaller (from 80 to $65 \%$ ); the reduction of $81 \%$ for

women with two biological children compared with childless women at

CSP 2010, 37.3-4: $375-410$ 
the time of the union, becomes $40 \%$. The differences between other categories do not seem to be affected by contraceptive sterilization, probably because the recourse to such contraceptive method did not differ strongly between these categories.

Table 8

Percentage of Women Aged 40-49 being Sterilized at the beginning of the Union, and Percentage who had a Common Child in the Union, among Couples with at least one Spouse in a 2nd Union+, for Canada and Regions: GSS, 2001

\begin{tabular}{lcccc}
\hline Region & $\begin{array}{c}\text { Percent } \\
\text { Sterilized }\end{array}$ & Number & $\begin{array}{c}\text { Percent with } \\
\text { Common } \\
\text { Child }\end{array}$ & Number \\
\hline Canada & 26 & 527 & 42 & 550 \\
Atlantic & 21 & 92 & 48 & 94 \\
Québec & 28 & 99 & 39 & 104 \\
Ontario & 25 & 144 & 38 & 153 \\
Prairies & 30 & 100 & 44 & 104 \\
BC & 22 & 92 & 50 & 95 \\
\end{tabular}

Source: Calculations by authors from Statistics Canada, General Social Survey, 2001.

\section{Discussion and Conclusion}

The analysis showed noticeable fertility differences between Québec and other Canadian regions for the cohorts aged 40-49 in 2001, differences in the average number of children cohorts had, but more substantial ones in the parity progression ratios, particularly in $\mathrm{a}_{2}$. The lowest fertility (Québec) is characterized by a lower percentage of women having a second and a third child. Differentials in the conjugal history are part of the explanation, in particular living as a couple seemed more attractive and union stability more frequent, as was the case in the most Canadian regions, compared with Québec. Moreover one of the main features defining the relationship between conjugal history and fertility resides in the higher probability of having a third child, among those who have at least two, for women who had unstable unions, when compared with couples still in their first union at the end of their reproductive life. This 
difference is highest in the Canadian Prairies, but almost nonexistent in Québec.

Choosing sterilization does not seem to be tightly related to the fertility levels reached by the cohorts as a whole. For example, among Canadian regions, Ontario has the lowest percentage of women belonging to a sterilized couple, but an average number of children equal to the Canadian mean. By contrast, Québec with the lowest fertility is among the highest regions for the percentage sterilized with the Prairies and the Atlantic region, which have higher fertility than average. Multivariate analysis of sterilization use has shown that regional differences hold when controlled by individual fertility levels among couples in first stable unions, not among women in a couple with at least one spouse in a second + union. It has to be noticed that fertility already achieved by women is by far the strongest driving force behind the choice of sterilization: for stable couples, there is a $38 \%$ increase in the probability of becoming part of a sterilized couple for women having 3 or more children when compared with those who had 2 children. Moreover among women in a couple with at least one spouse in a second + union, women with one or two children before the current union are respectively 2 and 5 times more likely to become part of a sterilized couple during the current union than women who were childless at the beginning. These results suggest that contraceptive sterilization is a welcome mean of contraception when fertility desires are achieved, in agreement with what the literature shows.

On the other hand, couples with at least one spouse in a second union+ are more likely to have a child together, if neither partner have a child or have only one at the beginning of the union. Among those who were not already sterilized at the beginning, more than $40 \%$ had a child in that union. This percentage illustrates the importance of fertility desires among couples who had a more complex conjugal trajectory, this desire being more often realized when women did not have any children or only one before the current union. It then points at the group most susceptible to have regrets: those who were already a sterilized couple at the beginning of the current union. They represent around 5\% of the cohort $(19 \%$ of women in a couple with at least one spouse in a second unions + multiply by $26 \%$ belonging to a sterilized couple at the beginning of the union). We cannot determine whether couples who were already sterilized at the time of the second union were as likely as others who were still fertile to want to have a child with their new partner.

But this group is not the only one susceptible to feel regret. Among couples still in their first union, those who decided to use sterilization at the same time as their last birth also constitute a group that 
may change their minds and cannot easily do so; they represent about $16 \%$ of the cohort (58\% still in first union multiply by $28 \%$ ).

More generally, fertility decisions can be altered by changing circumstances, and couples or individuals who choose sterilization may at some time feel regrets, in particular if they make that choice at an early age or when they have few children. The possibility of changing your mind about having one more child or not constitutes an element of freedom that one looses with sterilization, which is quasi irreversible. But our analysis and the data that we have does not allow for concluding on a definite negative impact on fertility. Research on regrets after sterilization indicates that this may be the case, but more information on contemporary behaviour is necessary, especially because individuals with complex conjugal and family trajectories are becoming a larger proportion of adults in their reproductive age To deepen our understanding of these questions, more research has to be undertaken in particular on the motivations behind the decision to use sterilization. A qualitative survey among Quebec and French women and men who were sterilized is underway (Charton and Lapierre-Adamcyk 2008a, 2008b); interviews have been completed, and early analysis gives us insights about the reasons why sterilization is chosen.

Four groups of reasons were provided (Charton 2010a, 2010b): (1) For some people, the sterilization has been chosen as a method of contraception, for its efficiency and its security aspect, because it is considered as economic and/or because it is considered as natural, insinuating without constraint. Sterilized people feel liberated from some religious, political, patriarchal, and also medical constraints. (2) For others, sterilization is as their inaugural event to move from one procreative potential state to another. Some people have said to have needed to stop their procreative potential for being able to invest more in their intimate relationships, already existing family and/or work. (3) Sterilization is also presented for some people as the means to follow some implicit social norms, such as considering to have reached the age limit to have a child $(30,40,50)$, to have reached an ideal family size (usually two, and preferably a child of each sex) or also to avoid too long a gap between children, a gap no longer than two years between births, and then, sterilization ensures that all children are born from the same partners. (4) Finally, some people reported to have opted for sterilization for reasons related to gender relations, especially because this method allows the sharing of contraceptive/reproductive responsibilities; sterilization allows to overcome the gender condition, and because this method has some interests and sexual benefits. Beyond the influence that a choice of contraception can have on fertility decisions, analyzing the type of contraceptive methods used, also allows to high light social issues 
associated with contraceptive practices and choices (Charton 2008). These aspects need to be studied more deeply in the future.

\section{Acknowledgements}

This article is a revised version of a paper presented at the 2007 Canadian Population Society Meeting in Saskatoon. It is part of a project included in the Partenariat Famille en mouvance et dynamiques intergénérationnelles research programme financed by the Fonds québécois de recherche sur la culture et la société (FQRSC); it also benefited from a SSHRC grant. Responsibility for any errors rests with the authors.

\section{End Notes}

1. Childless women were not considered because the number of cases is too small.

\section{References}

Barone, M. A., C. H. Johnson, M. A. Luick, D. L. Teutonico and R. J. Magnani. 2004. Characteristics of men receiving vasectomies in the United States, 1998-1999. Perspectives on Sexual and Reproductive Health 36(1): 27-33.

Bélanger, A. and G. Ouellet, 2001. A comparative study of recent trends in Canadian and American fertility, 1980-1999, in Report on the Demographic Situation in Canada 2001. Cat. 91-209. Ottawa: Statistics Canada.

Brown, S. S. and L. Eisenberg. 1995. The Best Intentions: Unintended Pregnancy and the Well-Being of Children and Families. Washington, D.C.: National Academy Press. 
Bumpass, L. L., E. Thomson and A. L. Godecker. 2000. Women, men and contraceptive sterilization. Fertility and Sterility 73(5): 937-946.

Chapel Hill Tubal Reversal Center. 2009. http://www.tubalreversal.net/sterilization-regret.htm updated 2009-07-08.

Charles, E. 1948. The Changing Size of the Family in Canada. 1941 Census Monograph. Ottawa: Dominion Bureau of Statistics.

Charton, L. 2010a. Contraception et rapports sociaux de sexe: réflexions à partir de l'histoire contraceptive de personnes stérilisées en France et au Québec. Colloque La contraception: enjeux biomédicaux et sociaux, Congrès de l'Acfas, Montréal, Quebec. (May 12, 2010).

Charton, L. 2010b. Contraception et hétérosexualité: réflexions à partir de l'histoire contraceptive de personnes stérilisées en France et au Québec. Colloque Le rôle des médias, des nouvelles technologies et de l'environnement social dans le façonnement des représentations de la sexualité et des conduites sexuelles, Congrès de l'Acfas, Montréal, (May 14, 2010).

Charton, L. 2008. La stérilisation contraceptive: quelques considérations éthiques. Revue des Sciences sociales Ethique et Santé, 39: 96-103.

Charton, L. and E. Lapierre-Adamcyk. 2008a. Systèmes de valeurs et méthodes contraceptives: mise en perspective à partir du recours à la stérilisation contraceptive en France et au Québec. Colloque Internationale de l'Aidelf, Québec.

Charton, L. and E. Lapierre-Adamcyk. 2008b. Male versus Female Sterilization: a Comparative Study of this Decision in Québec and France. Poster at Population Association of America. New Orléans. http://partenariatfamilles.inrsucs.uquebec.ca/DocsPDF/Af fiche.pdf

Charton, L. and E. Lapierre-Adamcyk. 2007. Nonreversible Contraceptive Methods: A Comparative Study of Tubal Ligation and Vasectomy in Quebec and France. Poster at Population Association of America, New York. 
Godecker, A. L., E. Thomson and L. L. Bumpass. 2001. Union status, marital history and female contraceptive sterilization in the United States. Family Planning Perspectives 33(1): 35-41.

Henripin, J. 1968. Tendances et facteurs de la fécondité au Canada. 1961 Census Monograph, Ottawa: Dominion Bureau of Statistics.

Henripin, J. 2003. La métamorphose de la population canadienne. Montréal: Editions Varia. Collection Histoire et Société.

Kaufman, G. 1998. Sterilization of married couples: Husband versus wife sterilization. Journal of Biosocial Science 30(1): 1-14.

Krishnan, V. 2004. Contraceptive sterilization among Canadians, 19841995. Canadian Studies in Population 31(1): 15-31.

Lapierre-Adamcyk, E. and L. Charton. 2007. Fertility in Canadian Regions and Contraceptive Sterilization. Paper presented at the annual meeting of the Canadian Population Society, Saskatoon, June 2007.

Liu, K. E. and W. A. Fisher. 2002. Canadian physicians' role in contraception from the 19th century to now. Journal of Obstetrics Gynaecology Canada 24(3): 239-44.

Marcil-Gratton, N. 1988. Sterilization regret among women in metropolitan Montreal. Family Planning Perspectives 20(5): 222-227.

Marcil-Gratton, N. 2000. De l'interdiction à la libéralisation: les paradoxes entourant le recours à la stérilisation en Amérique du Nord, in Les enjeux de la stérilisation, edited by A Giami and H. Leridon. Collection Questions santé publique, Paris: INSERM/INED.

Marcil-Gratton, N. and É. Lapierre-Adamcyk. 1989. L'Amérique du Nord à l'heure de la troisième révolution contraceptive: la montée spectaculaire de la stérilisation au premier rang des méthodes utilisées. Espace, Populations, Sociétés 2: 239-248.

Morgan, S. P. and M. G. Taylor. 2006. Low fertility at the turn of the twenty first century. Annual Review of Sociology 32: 375-399. 
Nervo, P., L. Bawin, J. M. Foidart and M. Dubois. 2000. Regret after tubal sterilization. Journal de Gynécologie, Obstétrique et Biologie de la Reproduction 29(5): 485-491.

Potts, M. 1997. Sex and the birth rate: human biology, demographic change, and access to fertility-regulation methods. Population and Development Review 23(1): 1-39.

Ram, B. 2007. Fertility Decline and Social Change: New Trends and Challenges, in The Changing Face of Canada, edited by R. P. Beaujot and D. Kerr. Toronto: Canadian Scholar's Press, pp. 2042.

Worcester, S. 2003. Markers for sterilization regret include prodding partner, young age. OB/GYN News, July. 